\title{
Photon Attenuation Coefficients of Fly-Ash Based Geopolymers Synthesized with Different Barite Proportions
}

\author{
Sabri M. Shalbi, A.M. Al-Jarrah, M. S. Jaafar, and Naser M. Ahmed
}

\section{ABSTRACT}

\begin{abstract}
Mass attenuation coefficients of fly-ash based geopolymers fabricated with different proportions of barite are measured using a high-resolution NaI spectrometer detector. After fabrication, the samples were irradiated with gamma-rays emitted from point sources of ${ }^{241} \mathrm{Am}$ and $1^{37} \mathrm{Cs}$. The measured experimental values are found to be consistent with theoretical calculations carried out using the XCOM program. Based on the results, the radiation shielding capacity of the geopolymers is found to increase with increase in barite proportion. In addition, the fly-ash based geopolymers fall within the internationally established range and are thus acceptable for use as radiation protection devices.
\end{abstract}

Keywords: Radiation Protection, Fly-Ash, Geopolymers, Shielding Material.

\section{INTRODUCTION}

The materials normally used for shielding harmful effect of radiation include ordinary concrete, heavy concrete, lead, steel, polyethylene, paraffin, and wood. Concrete has several benefits over different substances, consisting of its provision of powerful X-ray protection, proper structural strength, and comparatively economic. Similarly, lead is characterized through a completely excessive density and is an excellent Xand gamma-ray protective material, even though its toxicity function is the main situation given its heavy nature, in particular as regards occupational exposure. Contrary to concrete substances, metallic is pricey however is non-toxic. Steel is extra powerful in comparison to concrete as an X-and gamma-ray protective material, however much less green than lead. Wood is less expensive and calls for easy strategies to fabricate, even though it has low density [1], [2]. On the alternative hand, concrete is the supply of about $7 \%$ of $\mathrm{CO} 2$ emission into the atmosphere, which in flip contributes approximately $65 \%$ of worldwide warming [3]. In addition, constructing substances are the second main supply of indoor radon pollution, at the back of soil, with concrete some of the
Published Online: July 06, 2021

ISSN: $2684-4451$

DOI : 10.24018/ejphysics.2021.3.4.84

\section{Sabri M. Shalbi}

Department of Radiology, Higher Institute Sciences Medical, Elkhomes, Libya.

(e-mail: Sabri00218@yahoo.com)

A. M. Al-Jarrah*

Engineering Technology \& Science Division, Sharjah Higher Colleges of Technology, P.O Box 7947, Sharjah, United Arab Emirates.

(e-mail: aaljarrah@hct.ac.ae)

M. S. Jaafar

School of Physics, Universiti Sains Malaysia, 11800 USM Penang,

Malaysia.

(e-mail: msj@usm.my)

Naser M. Ahmed

School of Physics, Universiti Sains

Malaysia, 11800 USM Penang,

Malaysia.

(e-mail: naser@usm.my)

*Corresponding Author maximum contributors [4], [5]. The exhalation of radon and progenies from indoor concrete surfaces has been proven to make contributions to as much as $30 \%$ of the whole indoor radioactive pollution [6]. The primary goal of radiation safety is to guard humankind against the dangerous effect of ionizing radiation, without overly restraining the treasured practices of such exposures like radiation clinical packages use [7]. There is increasing use of radiation technologies, particularly radioactive isotopes, and accelerators in numerous fields of science.

Hence, there is the need to use these technologies with extreme caution, only after having different effective protective shields. Therefore, it is imperative to study the level of protection the public can get while in their homes. For this reason, two main points are generally considered in the field of building construction: resistance against earthquake expressed as strength of the building, and resistance against radiation expressed as $\gamma$-ray attenuation [8].

The correct values of mass attenuation coefficients for Xand $\gamma$-rays in numerous substances are important in fields of nuclear and radiation physics, radiation dosimeter, further to 
biological, medical, agricultural, and business applications. There is a big extent of experimental and theoretical research of mass attenuation coefficients [9]. For example, Türkmen et al. [10] calculated attenuation coefficients in Portland cement blended with silica fume, blast furnace slag, and herbal zeolite over the variety of $1-2000 \mathrm{keV}$. Singh et al. [11] decided attenuation coefficients of barium-borate fly ash glasses used as safety in opposition to radiation in the location of concrete. Awadallah and Imran [12] measured gamma-ray attenuation coefficients for limestone, bricks, and urban in Jordan. Similarly, Salinas et al. [13] calculated the powerful density and mass attenuation coefficients for some of constructing substances normally utilized in Brazil. Akkurt et al. [14] calculated attenuation coefficients of barite, marble, and limra in Turkey. Alam et al. [15] measured the attenuation coefficients for soil samples and constructing substances in Bangladesh. Meckbach et al. [16] used the Monte Carlo technique to look at the defensive of gamma radiation via way of means of numerous forms of homes in the European continent. The importance of $\gamma$-ray lies withinside the reality that it may effortlessly penetrate into the matter because it's miles uncharged and has no mass, and hence hard to shield. The interplay of $\gamma$-rays relies upon the incoming photon energy. The linear attenuation coefficients $(\mu)$, defined because the possibility of radiation interacting with the material in step with unit path length is the maximum vital parameter that characterizes the penetration and diffusion of gamma radiation in a medium. The value of linear attenuation coefficients relies upon a variety of things that encompass incident photon energy, atomic range, and density of the defensive substances. Given that the linear attenuation coefficients rely upon the density $(\rho)$, its miles expressed as a mass attenuation coefficient $(\mu / \rho)$ which is the linear attenuation coefficient in step with the unit mass of the material [17].

Taking linear attenuation coefficients into consideration, Davidovits evolved amorphous to semi-crystalline aluminosilicate inorganic polymers withinside the 1980s, now called geopolymers. Geopolymers are inorganic cementitious binding gel shaped from the polymeric response among an aluminosilicate rich fabric and an alkali metallic hydroxide/silicate liquid, which may be used to encapsulate high-quality and coarse aggregates to provide concrete [18][22]. Davidovits [21] stated that geopolymers own excessive early strength, more suitable sturdiness, and pose no danger. Fly ash primarily based totally geopolymers have garnered hobby for the reason that Nineties due to its high-quality overall performance whilst uncovered to distinctive acids with various concentrations and publicity intervals in addition to its better compressive strength [23]. Fly ash geopolymer is based on fly ash and alkaline activator mixture of solution $(\mathrm{NaOH})$.

Geopolymer pastes may be commonly used as an opportunity binder to cement paste to provide concrete. Fly ash is a source fabric for geopolymer binders this is quite simply obtainable, however, its use so far is limited. More specifically, the worldwide coal ash production, primarily based totally on a 1998 estimation, handed 390 million tonnes annually, but its use fell under $15 \%$ [24]. Therefore, tries to make the most of this spinoff fabric withinside the manufacture of concrete is essential with the intention to make concrete extra environmentally pleasant [25]. A barium sulfate $\left(\mathrm{BaSO}_{4}\right)$ base, which possesses a demonstrated protecting impact, becomes selected as the principal fabric [8], [26], [27]. $\mathrm{BaSO}_{4}$ produces an amazing protecting impact best whilst its miles unfold uniformly over different substances because of its excessive density $\left(4.5 \mathrm{~g} / \mathrm{cm}^{3}\right)$. The intention of this look is to fabricate an economic, effortlessly possible, and environmentally pleasant radiation protecting substance the usage of Fly ash primarily based totally geopolymers combined with barium compounds. This looks at used $\mathrm{BaSO}_{4}$ as an opportunity to guide with the intention to expand an environmentally pleasant radiation protecting substances. The purpose become to expand a composition and procedure that beautify the porosity and protecting rate and compares the performance. This painting targets to offer experimental and theoretical values for gamma-ray attenuation coefficients required to validate the effectiveness of fly-ash primarily based totally on geopolymers mixed with barite. The look at additionally analyzes the protecting performance of those decided on substances over the chosen power range.

Fly ash primarily based on geopolymers is a crucial opportunity for standard cement. The manufacture of Portland cement is a rigorous manner that releases an excellent quantity of greenhouse fueloline (13500 million tons) to the atmosphere, which makes up approximately $7 \%$ of the greenhouse fueloline produced yearly [28]. Attempts have, thus, been made to sell the alternative of elements of the Portland cement with pozzolans. In the latest times, opportunity shape of cementitious substances the usage of silicon and aluminum activated in an excessive alkali answer changed into established [29]. Fly ash is generally used as a supply to increase this fabric and is called geopolymer or alkali-activated fly ash cement $[30,31]$. The mortar and urban advanced from this geopolymer show off electricity and shape analogous to the ones from traditional Portland cement. It is likewise identified that geopolymers own notable mechanical properties, fire resistance, and acid resistance [32]. Contemporary research at the fly ash primarily based totally on geopolymers was primarily based totally on the generally hired type-F low calcium fly ash [30]. Nonetheless, given its affordable quantity of silica and alumina, excessive calcium fly ash can also be relevant as a base fabric for making geopolymer. The understanding of excessive calcium lignite fly ash in generating geopolymer might be treasured to the information and destiny packages of this fabric.

\section{MATERIALS AND METHODS}

\section{A. Materials}

The substances used to fabricate the geopolymers consist of Lignite fly ash (FA) received from the Sha Alam energy station positioned in Malaysia, sodium hydroxide $(\mathrm{NaOH})$ concentration $10 \mathrm{M}$, and sodium silicate with $14.7 \% \mathrm{Na}_{2} \mathrm{O}$, $29.4 \% \mathrm{SiO}_{2}$, and $55.9 \% \mathrm{H} 2 \mathrm{O}$. Locally received river sand characterized via way of means of the particular gravity of 2 . Sixty-five beneath neath saturated floor dry conditions became used to make the mortar. Chemical compositions and loss on ignition (LOI) of the fly ash are laid out in Table I. The magnificence F- fly ash includes a reasonably big amount 
of calcium oxide and is reasonably coarse.

\begin{tabular}{ccc}
\multicolumn{2}{c}{ TABLE I: Chemical Composition OF FLy ASH AND CEMENT } \\
\hline \hline Composition & Fly Ash (\%) & Cement (\%) \\
\hline $\mathrm{SiO}_{2}$ & 54.18 & 22.47 \\
$\mathrm{Al}_{2} \mathrm{O}_{3}$ & 28.79 & 5.53 \\
$\mathrm{Fe}_{2} \mathrm{O}_{3}$ & 4.11 & 3.16 \\
$\mathrm{CaO}$ & 4.27 & 62.89 \\
$\mathrm{MgO}$ & 0.93 & 2.31 \\
$\mathrm{~K}_{2} \mathrm{O}$ & 0.48 & 0.43 \\
$\mathrm{TiO}_{2}$ & 0.35 & - \\
$\mathrm{Na}_{2} \mathrm{O}$ & 0.31 & 0.21 \\
$\mathrm{SO}_{3}$ & 0.22 & 1.94 \\
$\mathrm{~L} . \mathrm{O} . \mathrm{I}$ & 2.11 & 1.87 \\
\hline \hline
\end{tabular}

\section{B. Test Details}

When you submit your final version, after your paper has been accepted, prepare it in two-column format, including figures and tables.

\section{1) Mix Design and Mixing of Mortar}

The geopolymer mortars had been made with sand to fly ash ratio of two .75 . The sodium silicates to $\mathrm{NaOH}$ ratios through silica modulus (Ms) of two had been used. To gain a powerful geopolymer mortar, a minimal base water content material of five\% through the mass of the geopolymer paste (fly ash, $\mathrm{NaOH}$, sodium silicate, and base water) was used for all mixes. The blending turned into executed in an airconditioned room at about $25{ }^{\circ} \mathrm{C}$. $\mathrm{NaOH}$ answer, base water, and fly ash had been combined for five min the usage of a pan mixer. Sand turned into eventually added, and the integration method turned into repeated for any other five min. This turned into followed through the addition of sodium silicate solution and additional water or superplasticizer (to attain workability), observed through a final blending of an additional five min. Immediately after the integration method, the flow of the clean geopolymer mortar turned into decided in keeping with ASTM C124 [33].

\section{2) Compaction and Strength Test}

The clean mortar was positioned in metallic moulds with a size of fifty $\mathrm{mm} \times 50 \mathrm{~mm} \times 50 \mathrm{~mm}$. The specimens have been then compacted with two-layer putting and tamping as defined withinside the ASTM C109 [34]. This changed into observed through similarly vibration for $10 \mathrm{~s}$ the usage of a vibrating table. Afterwards, the specimens and moulds have been enfolded in vinyl sheet to prevent moisture loss. The specimens have been then positioned withinside the oven at $60{ }^{\circ} \mathrm{C}$ after a set postpone time. After curing at an increased temperature, the specimens have been deposited withinside the laboratory to settle down and ultimately de-moulded the next day and stored at $25-28{ }^{\circ} \mathrm{C}$ withinside the room till the checking out commenced. The compressive power exams have been accomplished after 28 days according with ASTM C109. The pronounced strengths are the measured common of 3 exams.

\section{3) Attenuations Measurements}

In a slender beam geometry with the usual gamma factor reasserts positioned in advance of the pattern, the attenuation coefficients were measured the usage of Beers Lambert's law: $\mathrm{I}=\mathrm{I}_{0} \mathrm{e}^{(-\mu \mathrm{x})}$, wherein $\mathrm{x}$ denotes the thickness of the pattern, $\mathrm{I}_{0}$ represents the variety of counts representing the depth of gamma-ray photons at selected energy, without attenuation, and I am the gamma-ray counts that penetrated the absorber with attenuation withinside the pattern. The calculation of the overall mass attenuation coefficients for exclusive constructing substances was accomplished with the XCOM laptop application advanced through Berger and Hubbell [35]. The utility provides usual cross-sections and attenuation coefficients similarly to partial cross-sections for the incoherent scattering, coherent scattering, photoelectric absorption, and pair production. To benefit values for the mass attenuation coefficient from the measured incident and transmitted gamma-ray intensities, it is far important to comprehend the thickness and density of each sample. The density and mass of each sample had been measured through the use of a Vernier caliper and balance (with the precision of $0.01 \mathrm{~g}$ ), respectively. Cement mortar samples were prepared from different mixtures of gravel, sand, cement, and waterbased totally mostly on a conventional method applied in Malaysia. While the barite percentage in fly-ash primarily based totally geopolymers samples become optimized through various the load fractions of the barite with inside the samples. The impact of barite inclusion at the attenuation coefficient of the samples changed into decided through various the load fractions of barite with inside the fly-ash batches, among $5 \%$ and $15 \%$ of the fly ash weight. Five batches (A, B, C, D, and E) of samples had been prepared; Table II suggests the chemical compositions and the common density of every investigated sample.

Gamma-ray measurements had been carried out with the use of a thallium-activated sodium iodide detector NaI (T1) (ORTEC, 2010) coupled to a multichannel analyzer (School of Physics, University Sains Malaysia) with a relative performance of $70 \%$ [36]. The detector's calibration was accomplished using IAEA-licensed popular sources; $241 \mathrm{Am}$ (59.5 keV) and137Cs (661.6 keV). The number of counts, with and without the studied samples, was recorded through the detector for a period of about $20 \mathrm{~min}$.

TABLE II: THE CHEMICAL COMPOSITIONS AND THE AVERAGE DENSITY OF EACH INVESTIGATED SAMPLES

\begin{tabular}{c|cccccccc}
\hline \hline & \multicolumn{7}{c}{ Weight composition for each batches in } \\
\hline $\begin{array}{c}\text { Batc } \\
\text { hes }\end{array}$ & $\begin{array}{c}\text { Density } \\
\mathrm{g} / \mathrm{cm}^{3}\end{array}$ & $\begin{array}{c}\text { Fly } \\
\text { ash }\end{array}$ & $\mathrm{BaSO}_{4}$ & sand & $\begin{array}{c}\mathrm{NaSi} \\
\mathrm{O}_{3}\end{array}$ & $\begin{array}{r}\text { Pe } \\
\text { llet }\end{array}$ & $\begin{array}{c}\text { Cemen } \\
\mathrm{t}\end{array}$ & water \\
\hline $\mathrm{A}$ & 1.66 & 0.0 & 0.0 & 637.5 & 0.0 & 0.0 & 240.0 & 122.5 \\
$\mathrm{~B}$ & 1.98 & 326.7 & 0.0 & 485.5 & 116.7 & 15.0 & 0.0 & 56.1 \\
$\mathrm{C}$ & 2.06 & 310.3 & 16.4 & 485.5 & 116.7 & 15.0 & 0.0 & 56.1 \\
$\mathrm{D}$ & 2.13 & 294.1 & 32.6 & 485.5 & 116.7 & 15.0 & 0.0 & 56.1 \\
E & 2.21 & 277.6 & 49.1 & 485.5 & 116.7 & 15.0 & 0.0 & 56.1 \\
\hline \hline
\end{tabular}

A: Cement mortar; B: Fly-ash based geopolymers; C: Fly-ash based geopolymers with 5\% barite; D: Fly-ash based geopolymers with 10\% barite; E: Fly-ash based geopolymers with $15 \%$ barite. 


\section{RESULTS AND DISCUSSION}

The mass attenuation coefficients $(\mu / \rho)$ for constructing materials samples are measured for the two energies: (59.5 and 661.6) $\mathrm{keV}$. The resultant experimental values of the mass attenuation coefficients, further to theoretical values calculated by the use of the XCOM program, are proven in Fig. 1 and 2. The most percent mistakes among the experimental and theoretical mass attenuation values are much less than $4 \%$. The calculated and measured mass attenuation coefficients for the investigated samples at $59.5 \mathrm{keV}$ are proven in Fig. 1.

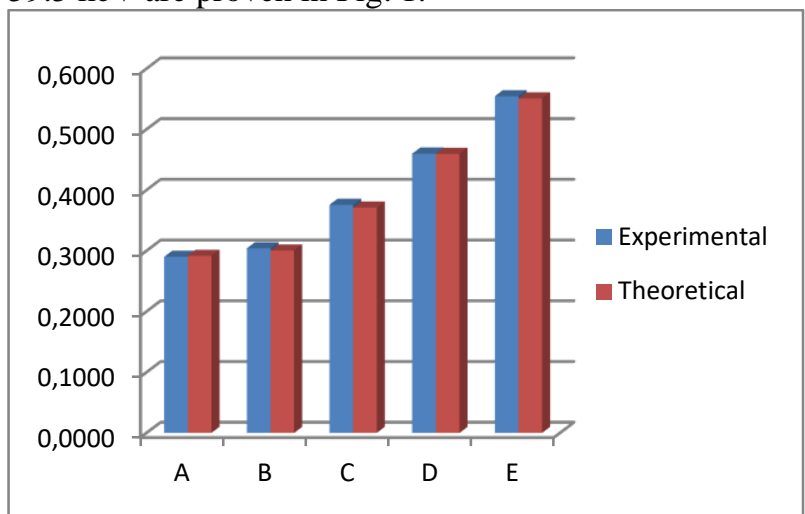

Fig. 1. The calculated and measured mass attenuation coefficients for the investigated samples at $59.5 \mathrm{keV}$.

It is obvious that the experimental and theoretical values are unvarying, no matter the truth that the experimental values have a tendency to be barely decreased than the theoretical values. Theoretically, this discovered variant is not always ascribed to variations withinside the chemical composition of the constructing substances because the factors involved possess comparable atomic numbers. This moderate version may want to as a substitute be an end result of deviations withinside the narrow beam geometry in the source-detector arrangements. Moreover, it's far perceptible that is their little distinction withinside the mass attenuation coefficients among fly-ash-primarily based totally geopolymers samples at $661.6 \mathrm{keV}$ as proven in Fig. 2 .

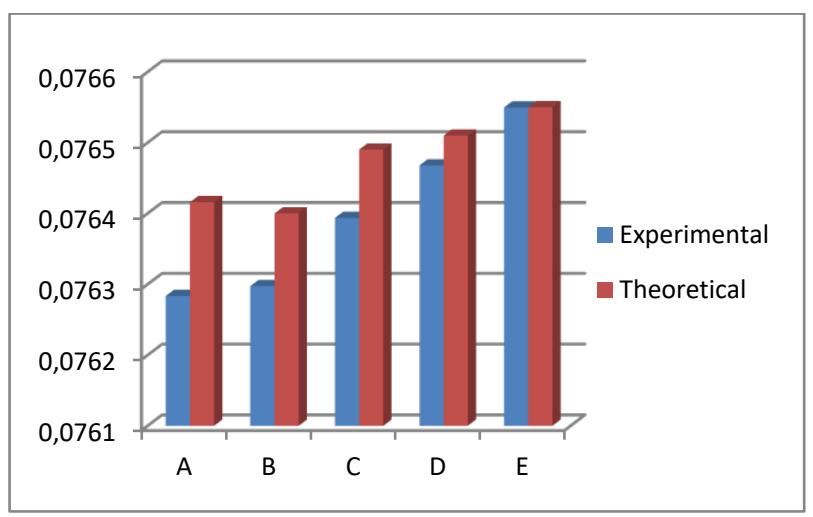

Fig. 2. The calculated and measured mass attenuation coefficients for the investigated samples at $661.6 \mathrm{keV}$.

This is possibly due to the similarity of the elemental compositions of the samples. However, distinct difference is observed for energy levels below $100 \mathrm{keV}$. The protection efficiency of fly-ash based geopolymers samples containing $15 \%$ barite is determined to be approximately $47 \%$ higher than usual cement mortar for energies not exceeding $100 \mathrm{keV}$.

\section{CONCLUSIONS}

This study presents an experimental and theoretical determination of mass attenuation coefficients for fly-ash based geopolymers combined with barite. The Fly-ash based geopolymers samples incorporated with $15 \%$ of barite displayed $\approx 47 \%$ higher shield radiation ability compared to cement mortar. These results can be applied to studies on different kinds of construction material able to shield radiation, particularly in contaminated or high background radioactivity regions.

\section{REFERENCES}

[1] P. R. Almond, "Shielding techniques for radiation oncology facilities, by Patton H. McGinley", Journal of Applied Clinical Medical Physics, Vol. 3, pp. 261-263, 2002.

[2] S. S. Design, Evaluation for Megavoltage X-and Gamma-Ray Radiotherapy Facilities. Washington: Pregamon Press, 2005.

[3] A. M. Rashad, "A comprehensive overview about the influence of different admixtures and additives on the properties of alkali-activated fly ash", Materials \& Design, vol. 53, pp. 1005-1025, 2014.

[4] Ş. Turhan, I. Arıkan, B. Yücel, A. Varinlioğlu, and A. Köse, "Evaluation of the radiological safety aspects of utilization of Turkish coal combustion fly ash in concrete production", Fuel, vol. 89, pp. 2528-2535, 2010.

[5] K. Folkerts, G. Keller, and H. Muth, "Experimental Investigation on Diffusion and Inhalation of 222Rn and 220Rn from Building Materials", Radiation Protection Dosimetry, vol. 7, pp. 41-44, 1984.

[6] M. S. Gadd, and T. B. Borak, "Partitioning of $222 \mathrm{Rn}$ entry into a structure surrounded by soil”, Health physics, vol. 67, pp. 53-9, 1994.

[7] F. F. Luykx, and M. J. Frissel, Radioecology and the Restoration of Radioactive-contaminated Sites, USA: Springer Science \& Business Media, 2012.

[8] I. Akkurt, C. Basyigit, S. Kilincarslan, and B. Mavi, "The shielding of $\gamma$-rays by concretes produced with barite", Progress in Nuclear Energy, vol. 46, pp. 1-11, 2005

[9] I, Han, and L, Demir, "Determination of mass attenuation coefficients, effective atomic and electron numbers for $\mathrm{Cr}$, Fe and $\mathrm{Ni}$ alloys at different energies", Nuclear Instruments and Methods in Physics Research Section B: Beam Interactions with Materials and Atoms, vol. 267, pp. 3-8, 2009

[10] İ. Türkmen, Y. Özdemir, M. Kurudirek, F. Demir, Ö. Simsek, and R. Demirboğa, "Calculation of radiation attenuation coefficients in Portland cements mixed with silica fume, blast furnace slag and natural zeolite", Annals of Nuclear Energy, vol. 35, pp.1937-1943. 2008.

[11] S. Singh, A. Kumar, D. Singh, K. S. Thind, and G. S. Mudahar, "Barium-borate-flyash glasses: as radiation shielding materials" Nuclear Instruments and Methods in Physics Research Section B. Beam Interactions with Materials and Atoms, vol. 266, pp. 140-146, 2008.

[12] M. I. Awadallah, and M. M. Imran, "Experimental investigation of $\gamma$ ray attenuation in Jordanian building materials using $\mathrm{HPGe}$ spectrometer", Journal of environmental radioactivity, vol. 94, pp 129-136, 2007.

[13] I. Salinas, C. Conti, and R, Lopes, "Effective density and mass attenuation coefficient for building material in Brazil", Applied Radiation and Isotopes, vol. 64, pp. 13-21, 2006.

[14] I. Akkurt, S. Kilincarslan, and C. "Basyigit. The photon attenuation coefficients of barite, marble and limra", Annals of Nuclear Energy, vol. 31, pp. 577-582, 2004

[15] M. Alam, M. Miah, M. Chowdhury, M. Kamal, S. Ghose, and R. Rahman, "Attenuation coefficients of soils and some building materials of Bangladesh in the energy range 276-1332keV", Applied Radiation and Isotopes, vol. 54, pp. 973-979, 2001.

[16] R. Meckbach, P. Jacob, and H. G. Paretzke, "Shielding of gamma radiation by typical European houses" Nuclear Instruments and Methods in Physics Research Section A: Accelerators, Spectrometers, Detectors and Associated Equipment, vol. 255, pp. 160-164, 1987.

[17] M, Medhat, "Gamma-ray attenuation coefficients of some building materials available in Egypt", Annals of Nuclear Energy, vol. 36, pp. 849-852, 2009.

[18] M. S. Salwa, A. Mustafa, A. Bakri, H. Kamarudin, C. Ruzaidi, and M Binhussain, "Review on Current Geopolymer as a Coating Material,

[19] Australian Journal of Basic and Applied Sciences, vol. 7, no. 5, pp. 246-257, 2013.

[20] J, Davidovits, Mineral polymers and methods of making them. Google Patents, 1982. 
[21] J. Davidovits, "Geopolymers", Journal of Thermal Analysis and calorimetry, vol. 37, pp. 1633-1656, 1991.

[22] J, Davidovits, "Properties of geopolymer cements", First international conference on alkaline cements and concretes, vol. 1, pp. 131-149, Kiev State Technical University, Ukraine, 1994.

[23] H. Xu, and J. Van Deventer, "The geopolymerisation of aluminosilicate minerals", International Journal of Mineral Processing, vol 59, pp. 247-266, 2000.

[24] U. Rattanasak, and P. Chindaprasirt, "Influence of $\mathrm{NaOH}$ solution on the synthesis of fly ash geopolymer", Minerals Engineering, vol. 22 , pp. 22:1073-1081, 2009.

[25] V. Malhotra, "Making concrete" greener" with fly ash", Concrete International, pp. 21, 1999

[26] D. Hardjito, S. E. Wallah, D. M. Sumajouw, and B. V. Rangan, "On the development of fly ash-based geopolymer concrete", ACI materials journal, vol. 101, no. 6, pp 467-472, 2004.

[27] S. C. Kim, K. R. Dong, and W. K. "Chung. Performance evaluation of a medical radiation shielding sheet with barium as an environmentfriendly material", Journal of the Korean Physical Society, vol. 60, pp. 165-70, 2012.

[28] N. Salah, S. S. Habib, Z. H. Khan, S. Al-Hamedi, and S. Lochab, "Nanoparticles of BaSO 4: Eu for heavy-dose measurements", Journal of Luminescence, vol 129, pp. 192-198, 2009.

[29] V. Malhotra, Introduction: sustainable development and concrete technology. Concrete International, vol. 24, no. 7, pp. 1-22, 2002.

[30] J. Davidovits, "Chemistry of geopolymeric systems, terminology", Geopolymer, vol. 99, no. 292, pp. 9-39, 1999.
[31] T. Bakharev, "Geopolymeric materials prepared using Class F fly ash and elevated temperature curing", Cement and Concrete Research, vol 35, pp. 1224-1232, 2005.

[32] A. Fernández-Jiménez, A. Palomo, and M. Criado, "Microstructure development of alkali-activated fly ash cement: a descriptive model", Cement and concrete research, vol. 35, pp. 1204-1213.

[33] A. Palomo, A. Macias, M. Blanco, and F. Puertas, "Physical, chemical and mechanical characterization of geopolymers", Proceedings of the 9th International Congress on the Chemistry of Cement, pp. 505-11. New Delhi, India, 1992.

[34] American Society for Testing and Materials. ASTM C124-71: Standard test method for flow of Portland cement concrete by use of the flow table, Annual book of ASTM standards, Part 10, Philadelphia; 1973.p.75-7.

[35] American Society for Testing and Materials. ASTM C109/C109M99: Standard test method for compressive strength of hydraulic cement mortars. Annual book of ASTM Standards, Philadelphia; 04.01, 2001. p. 83-8.

[36] M. Berger, and J. Hubbell. XCOM: Photon Cross Sections, NBSIR, Washington, DC (USA): Center for Radiation Research, 1987.

[37] A. Al-Jarrah, A. Azhar, S. Iskandar, N. N. A. N. Abrazak, B. Ababneh, and E. T. Tousi, "Effect of Sulfuric Acid Concentration on Radiological Properties of Genipin Gel Dosimeter", International Journal of Chemical, Environmental \& Biological Sciences, vol. 2, no. 2, pp. 136-140, 2014. 